\title{
ClOOCl photolysis at high solar zenith angles: analysis of the RECONCILE self-match flight
}

\author{
O. Sumińska-Ebersoldt ${ }^{1}$, R. Lehmann ${ }^{2}$, T. Wegner ${ }^{1}$, J.-U. Grooß ${ }^{1}$, E. Hösen ${ }^{3}$, R. Weigel ${ }^{4}$, W. Frey ${ }^{5}$, S. Griessbach ${ }^{6}$, \\ V. Mitev ${ }^{7}$, C. Emde ${ }^{8}$, C. M. Volk ${ }^{3}$, S. Borrmann ${ }^{4,5}$, M. Rex ${ }^{2}$, F. Stroh ${ }^{1}$, and M. von Hobe ${ }^{1}$ \\ ${ }^{1}$ Institut für Energie- und Klimaforschung: Stratosphäre (IEK-7), Forschungszentrum Jülich GmbH, Germany \\ ${ }^{2}$ Alfred-Wegener-Institut für Polar- und Meeresforschung, Potsdam, Germany \\ ${ }^{3}$ Fachbereich C - Abteilung Physik, Bergische Universität Wuppertal, Germany \\ ${ }^{4}$ Institut für Physik der Atmosphäre, Johannes Gutenberg Universität Mainz, Germany \\ ${ }^{5}$ Partikelchemie Abteilung, Max-Planck-Institut für Chemie, Mainz, Germany \\ ${ }^{6}$ Jülich Supercomputing Centre (JSC), Forschungszentrum Jülich GmbH, Germany \\ ${ }^{7}$ CSEM Centre Suisse d'Electronique et de Microtechnique SA, Neuchâtel, Switzerland \\ ${ }^{8}$ Meteorologisches Institut, Ludwig-Maximilians-Universität, München, Germany \\ Correspondence to: O. Sumińska-Ebersoldt (olga.suminska-ebersoldt@kit.edu)
}

Received: 13 May 2011 - Published in Atmos. Chem. Phys. Discuss.: 1 July 2011

Revised: 9 January 2012 - Accepted: 10 January 2012 - Published: 2 February 2012

\begin{abstract}
The photolysis rate constant of dichlorine peroxide $(\mathrm{ClOOCl}, \mathrm{ClO}$ dimer $) J_{\mathrm{ClOOCl}}$ is a critical parameter in catalytic cycles destroying ozone $\left(\mathrm{O}_{3}\right)$ in the polar stratosphere. In the atmospherically relevant wavelength region $(\lambda>310 \mathrm{~nm})$, significant discrepancies between laboratory measurements of $\mathrm{ClOOCl}$ absorption cross sections and spectra cause a large uncertainty in $J_{\mathrm{ClOOCl}}$. Previous investigations of the consistency of published $J_{\mathrm{ClOOCl}}$ with atmospheric observations of chlorine monoxide $(\mathrm{ClO})$ and $\mathrm{ClOOCl}$ have focused on the photochemical equilibrium between $\mathrm{ClOOCl}$ formation and photolysis, and thus could only constrain the ratio of $J_{\mathrm{ClOOCl}}$ over the $\mathrm{ClOOCl}$ formation rate constant $k_{\text {rec }}$. Here, we constrain the atmospherically effective $J_{\mathrm{ClOOCl}}$ independent of $k_{\mathrm{rec}}$, using $\mathrm{ClO}$ measured in the same air masses before and directly after sunrise during an aircraft flight that was part of the RECONCILE field campaign in the winter 2010 from Kiruna, Sweden. Over sunrise, when the $\mathrm{ClO} / \mathrm{ClOOCl}$ system comes out of thermal equilibrium and the influence of the $\mathrm{ClO}$ recombination reaction is negligible, the increase in $\mathrm{ClO}$ concentrations is significantly faster than expected from $J_{\mathrm{ClOOCl}}$ based on the absorption spectrum proposed by Pope et al. (2007), but does not warrant cross sections larger than recently published values by Papanastasiou et al. (2009). In particular, the existence of a significant $\mathrm{ClOOCl}$ absorption band longwards of $420 \mathrm{~nm}$ is not supported by our observations. The observed night-time
\end{abstract}

$\mathrm{ClO}$ would not be consistent with a $\mathrm{ClO} / \mathrm{ClOOCl}$ thermal equilibrium constant significantly higher than the one proposed by Plenge et al. (2005).

\section{Introduction}

Once chlorine is activated on polar stratospheric clouds (Solomon et al., 1986) or background aerosol (Drdla and Müller, 2010) in the polar stratosphere and sunlight is available, photochemical ozone loss occurs essentially via two catalytic cycles, the $\mathrm{ClO}$ dimer cycle (Molina and Molina, 1987):

$$
\begin{aligned}
& \mathrm{ClO}+\mathrm{ClO}+\mathrm{M} \underset{k_{\mathrm{diss}}}{\stackrel{k_{\mathrm{rec}}}{\rightleftharpoons}} \mathrm{ClOOCl}+\mathrm{M} \\
& \mathrm{ClOOCl}+h v \stackrel{J_{\mathrm{ClOOCl}}}{\longrightarrow} \mathrm{Cl}+\mathrm{ClOO} \\
& \mathrm{ClOO}+\mathrm{M} \rightarrow \mathrm{Cl}+\mathrm{O}_{2}+\mathrm{M} \\
& 2 \times\left(\mathrm{Cl}+\mathrm{O}_{3} \rightarrow \mathrm{ClO}+\mathrm{O}_{2}\right)
\end{aligned}
$$

$$
2 \mathrm{O}_{3}+h v \rightarrow 3 \mathrm{O}_{2}
$$


where $\mathrm{M}$ denotes a collision partner that is not affected by the reaction, and the ClO-BrO cycle (McElroy et al., 1986):

$$
\begin{aligned}
& \mathrm{BrO}+\mathrm{ClO}+h v \rightarrow \mathrm{Br}+\mathrm{Cl}+\mathrm{O}_{2} \\
& \mathrm{Br}+\mathrm{O}_{3} \rightarrow \mathrm{BrO}+\mathrm{O}_{2} \\
& \mathrm{Cl}+\mathrm{O}_{3} \rightarrow \mathrm{ClO}+\mathrm{O}_{2},
\end{aligned}
$$

$2 \mathrm{O}_{3}+h v \rightarrow 3 \mathrm{O}_{2}$

The forward and backward Reaction (R1) of the $\mathrm{ClO}$ dimer cycle, i.e. the $\mathrm{ClO}$ recombination and the $\mathrm{ClOOCl}$ thermal dissociation, govern the partitioning between $\mathrm{ClO}$ and $\mathrm{ClOOCl}$ in darkness with a thermal equilibrium constant

$K_{\mathrm{eq}}=\frac{k_{\mathrm{rec}}}{k_{\mathrm{diss}}}=\frac{[\mathrm{ClOOCl}]}{[\mathrm{ClO}]^{2}}$.

In daylight, Reactions (R2-R4) shift the chlorine oxides $\left(\mathrm{ClO}_{\mathrm{x}}=\mathrm{ClO}+2 \times \mathrm{ClOOCl}\right)$ partitioning towards the monomer and drive chemical ozone loss (Reaction R4). The $\mathrm{ClOOCl}$ photodissociation (Reaction $\mathrm{R} 2$ ) is the rate-limiting step of the $\mathrm{ClO}$ dimer cycle under twilight conditions that prevail throughout most of the winter in the polar stratosphere. By governing the $\mathrm{ClO}$ concentration [ClO], Reaction (R2) also limits the rate of Reaction (R5) in the ClO-BrO cycle, making the $\mathrm{ClOOCl}$ photolysis rate constant $J_{\mathrm{ClOOCl}}$ by far the most critical kinetic parameter for the overall ozone loss rate (von Hobe, 2007; Kawa et al., 2009).

$J_{\mathrm{ClOOCl}}$ is a product of the $\mathrm{ClOOCl}$ photolysis cross section and the actinic flux $I(\lambda)$ (Fig. 1b) integrated over wavelength:

$$
J_{\mathrm{ClOOCl}}=\int \sigma_{\mathrm{ClOOCl}}(\lambda) \cdot \phi(\lambda) \cdot I(\lambda) \cdot d \lambda
$$

The ClOOCl photolysis cross section is denoted in Eq. (2) as a product of absorption cross section $\sigma_{\mathrm{ClOOCl}}(\lambda)$ and the photolysis quantum yield $\phi(\lambda)$, i.e. the fraction of absorbed photons leading to photodissociation.

Photolysis cross sections have been determined by monitoring the disappearance of $\mathrm{ClOOCl}$ (Chen et al., 2009; Lien et al., 2009; Jin et al., 2010) or the appearance of $\mathrm{Cl}$ atoms (Wilmouth et al., 2009) in photolysis experiments at discrete wavelengths. For the entire wavelength range relevant for $\mathrm{ClOOCl}$ photolysis in the stratosphere $(\lambda>310 \mathrm{~nm})$, absorption cross sections (Cox and Hayman, 1988; DeMore and Tschuikow-Roux, 1990; Burkholder et al., 1990; Bloss et al., 2001; Papanastasiou et al., 2009) or relative absorption spectra (Huder and DeMore, 1995; von Hobe et al., 2009; Pope et al., 2007) have been measured by UV/Vis absorption spectroscopy.

Laboratory and theoretical studies show, that excited states of $\mathrm{ClOOCl}$ are rapidly dissociative (Birk et al., 1989; Moore et al., 1999; Kaledin and Morokuma, 2000; Toniolo et al.,

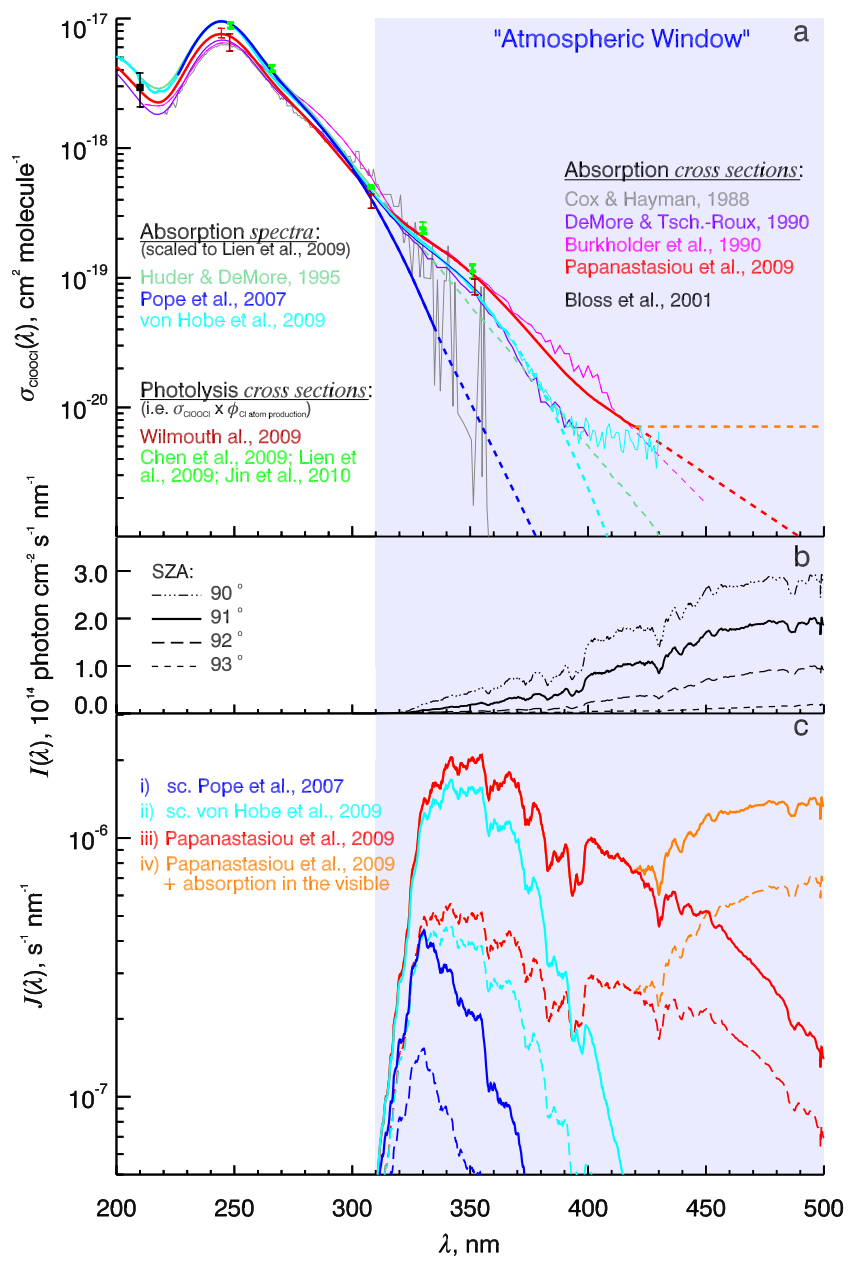

Fig. 1. The upper panel presents a comparison of UV/Vis absorption spectra, absorption cross sections and photolysis cross sections of $\mathrm{ClOOCl}$ from various studies. The dashed extensions show the exponential extrapolation of chosen spectra in the actinic region. Spectra i-iv (cf. Sect. 2.4) used in this study are shown with thicker lines, with the artificial spectrum for examination of the hypothesis of a $\mathrm{ClOOCl}$ absorption band in the visible represented by a dashed orange line. The middle panel shows spectral actinic flux $I(\lambda)$ calculated for four solar zenith angles. The photolysis rate constants estimated for absorption cross sections and spectra $\mathrm{i}-\mathrm{iv}$ and solar zenith angle (SZA) equal $91^{\circ}$ (solid line) and $92^{\circ}$ (dashed line) are shown in panel (c).

2001; Peterson and Francisco, 2004; Huang et al., 2011) and assume $\phi(\lambda)$ between 0.9 and 1. In Fig. 1a, photolysis cross sections are plotted under the assumption, that the quantum yield $\phi(\lambda) \sim 1$ for the entire wavelength range, i.e. absorption and photolysis cross sections are to be equivalent. JPL 2011 (Sander et al., 2011) recommends the photolysis and absorption cross sections for $\mathrm{ClOOCl}$ to be identical. The focus has shifted to the product yield of the photolysis reaction, i.e. Reaction (R2) versus production of two $\mathrm{ClO}$ molecules. While this does affect ozone loss by the dimer cycle, it has 
no influence on $\mathrm{ClO}_{\mathrm{x}}$ partitioning (and thus cannot be constrained in this study).

The laboratory studies, in which absorption spectra have been measured, are lacking the knowledge of the amount of $\mathrm{ClOOCl}$ present in the absorption cell and the relative spectra have to be scaled to one of the absolute cross sections. Figure 2 shows the peak absorption cross sections determined in various laboratories. Cox and Hayman (1988), DeMore and Tschuikow-Roux (1990) and Burkholder et al. (1990) determined peak absorption cross sections of $\mathrm{ClOOCl}$ at $245 \mathrm{~nm}$ between $5.8 \times 10^{-18}$ and $7.2 \times 10^{-18} \mathrm{~cm}^{2}$ molecule ${ }^{-1}$. According to the results of Papanastasiou et al. (2009), the absorption peak is at $244.5 \mathrm{~nm}$ and has a value of $7.6 \times 10^{-18} \mathrm{~cm}^{2}$ molecule ${ }^{-1}$, Wilmouth et al. (2009) placed the cross section peak of $6.6 \times 10^{-18} \mathrm{~cm}^{2}$ molecule ${ }^{-1}$ at $248.0 \mathrm{~nm}$, whereas studies of Lien et al. (2009) showed an even higher photolysis cross section $\left(8.85 \times 10^{-18} \mathrm{~cm}^{2}\right.$ molecule $\left.{ }^{-1}\right)$ close to the assumed peak, at $248.4 \mathrm{~nm}$. Here, we chose to scale all relative absorption spectra to the cross section of Lien et al. (2009) for two reasons:

1. Lien et al. (2009) have used a novel approach in which a molecular beam of $\mathrm{ClOOCl}$ is attenuated through photolysis by laser light. The method is insensitive to UV absorption interference by impurities and does not require information on the absolute $\mathrm{ClOOCl}$ concentration.

2. It seems unreasonable to scale a relative absorption spectrum to an absolute cross section associated with a different spectral shape, because then the two studies are contradictory, and it makes no sense to scale one to the other. For example, the shapes of the von Hobe et al. (2009) and the Papanastasiou et al. (2009) curves look so different that at least one of the two must be incorrect. Now, if Papanastasiou et al. (2009) were correct, then there is no need to scale any other spectral shapes to its peak cross sections. If, on the other hand, the results of von Hobe et al. (2009) were right, then the spectral shape was not measured correctly by Papanastasiou et al. (2009). And because spectrum peak cross section are not determined independently in that study, chances are that the peak cross sections would also be erroneous. Using the different spectral shape as an argument against scaling to some other absolute cross sections, we do note that the von Hobe et al. (2009) spectrum scaled to Lien et al. (2009) also does not fully agree with the cross sections at longer wavelength proposed by the same group from Taiwan (Chen et al., 2009; Jin et al., 2010). However, the molecular beam cross section measurements represent independent experiments at five different wavelengths, and they represent photolysis rather than absorption cross sections. More importantly, the Taiwan group observed significant temperature dependencies at the different wave-

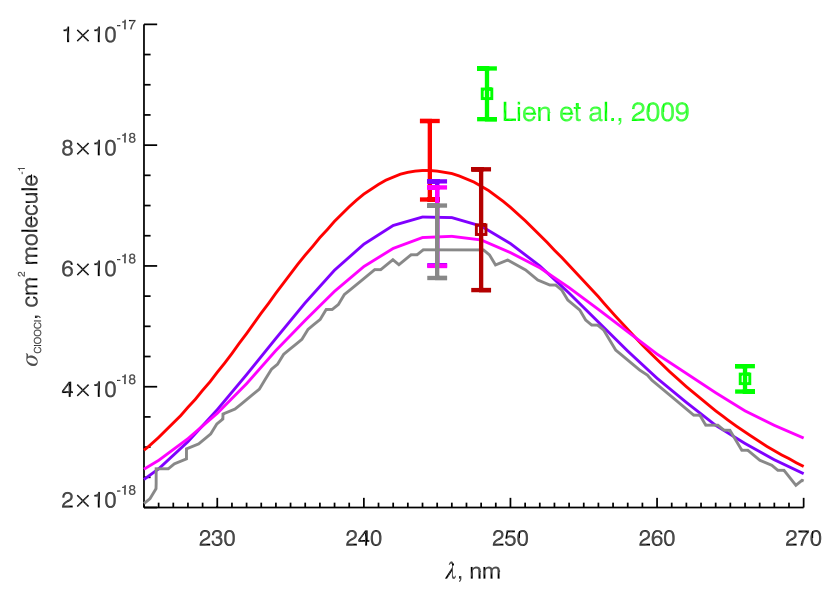

Fig. 2. Peak close-up for Fig. 1a. The colours of lines and squares correspond to the absorption cross sections and photolysis cross sections plotted in Fig. 1a, respectively.

length. At low temperatures (and the observations in the neon matrix clearly represent the lowest temperature $\mathrm{ClOOCl}$ cross section measurements), their cross sections at $248 \mathrm{~nm}$ are larger and their cross sections in the long wavelength tail are smaller than at higher temperatures in the gas phase, which can probably explain much of the disagreement described above.

Figure 1a shows that the existing laboratory studies of $\sigma_{\mathrm{ClOOCl}}$ display large uncertainties especially in the long wavelength tail, i.e. in the region most relevant in the atmosphere. These uncertainties propagate directly into the atmospheric $J_{\mathrm{ClOOCl}}$ values. Figure $1 \mathrm{c}$ reveals the significance of the photolysis longward of $400 \mathrm{~nm}$ at high solar zenith angles (SZA) and thus emphasizes the importance of the increasingly small cross sections in this wavelength region.

Previous studies investigating the consistency of $J_{\mathrm{ClOOCl}}$ resulting from laboratory measurements with atmospheric observations of $\mathrm{ClO}$ and $\mathrm{ClOOCl}$ have focused on the photochemical equilibrium between $\mathrm{ClOOCl}$ formation and photolysis rate. Stimpfle et al. (2004) tested different combinations of $J_{\mathrm{ClOOCl}}$ and $k_{\text {rec }}$ through comparison of the resulting $\mathrm{ClO}$ and $\mathrm{ClOOCl}$ with in-situ data. They investigated pairs of parameters and proposed a few combinations consistent with measured data, they ruled out photolysis of $\mathrm{ClOOCl}$ longwards of $800 \mathrm{~nm}$. Von Hobe et al. (2007) analysed available laboratory and field data and estimated limits for $J_{\mathrm{ClOOCl}}$ (Burkholder et al., 1990; Sander et al., 2006), $k_{\text {rec }}$ and $K_{\text {eq }}$. Schofield et al. (2008) derived $J_{\mathrm{ClOOCl}} / k_{\text {rec }}$ from $\mathrm{ClO}$ data measured during a flight, in which the aircraft encountered the same air masses twice. The flight pattern was named "self-match" and enabled observation of change in $\mathrm{ClO}$ mixing rations due to increasing solar zenith angle during sunset. Schofield et al. (2008) proposed a wide range of parameters fitting their data. Using $\mathrm{ClO}$ microwave radiometer data, Kremser et al. (2011) showed that $J_{\mathrm{ClOOCl}} / k_{\mathrm{rec}}$ should 
be between 1.23 and 1.97 times the value for $J_{\mathrm{ClOOCl}} / k_{\mathrm{rec}}$ recommended by JPL 2006 (Sander et al., 2006).

In our study, we followed the self-match method presented by Schofield et al. (2008), but started the flight in the night, when the air masses were in thermal equilibrium, and observed the change in $[\mathrm{ClO}]$ with decreasing solar zenith angle during sunrise. To ensure, that $\mathrm{ClO}$ was measured twice in the same air masses, a detailed check of match quality was carried out. The atmospheric parameters critical for actinic flux used for $J_{\mathrm{ClOOCl}}$ calculations were also investigated. From the observed $[\mathrm{ClO}]$ increase, $J_{\mathrm{ClOOCl}}$ was estimated and compared with $[\mathrm{ClO}]$ increases resulting from four sets of $\mathrm{ClOOCl}$ absorption cross sections/scaled spectra obtained for the atmospheric conditions prevailing during the flight.

The self-match flight pattern and the measurements are described in Sects. 2.1 and 2.2. Section 2.3 describes in detail the approach employed to test the consistency of the four different $J_{\mathrm{ClOOCl}}(\lambda)$ values presented in Sect. 2.4 with the observed rise in $[\mathrm{ClO}]$ over sunrise. In Sect. 2.5 actinic flux sensitivity analysis is described. An assessment of the success in resampling the same air in the matches based on observations of a chemically and dynamically conserved tracer and the results of the $\mathrm{ClO} / \mathrm{ClOOCl}$ kinetic studies will be presented in Sect. 3.

\section{Experiment description}

\subsection{The self-match flight}

The idea behind a self-match flight is to sample the same air masses twice during outbound and inbound flight legs of the same flight as described by Schofield et al. (2008). The flight analysed here was carried out on 30 January 2010 from Kiruna $\left(67^{\circ} 49^{\prime} \mathrm{N}, 20^{\circ} 20^{\prime} \mathrm{E}\right)$, Sweden, as part of the large aircraft field campaign within the European project RECONCILE (von Hobe et al., 2012), employing the Russian research aircraft M-55 Geophysica with a ceiling altitude of $20 \mathrm{~km}$. Flight track and match-pair trajectories are shown in Fig. 3.

To analyse the SZA dependence of $J_{\mathrm{ClOOCl}}$, the flight was carried out over sunrise, with the first measurements still in darkness (i.e. with no active photolysis reactions and the chemical system expected to be in thermal equilibrium), and the second "matching" measurements in daylight. The outbound flight was in westward direction and the inbound flight in eastward direction, moving from higher to lower solar zenith angles (i.e. increasing solar radiation and photolysis rates). Location and timing of the flight were planned as to direct the aircraft into a region of elevated $\mathrm{ClO}_{\mathrm{x}}$, identified prior to the flight using the Chemical Lagrangian Model of the Stratosphere (ClaMS, see Sect. 2.3) in the forecast mode. Air mass trajectories for the motion of individual air parcels between the two encounters were calculated based on opera-

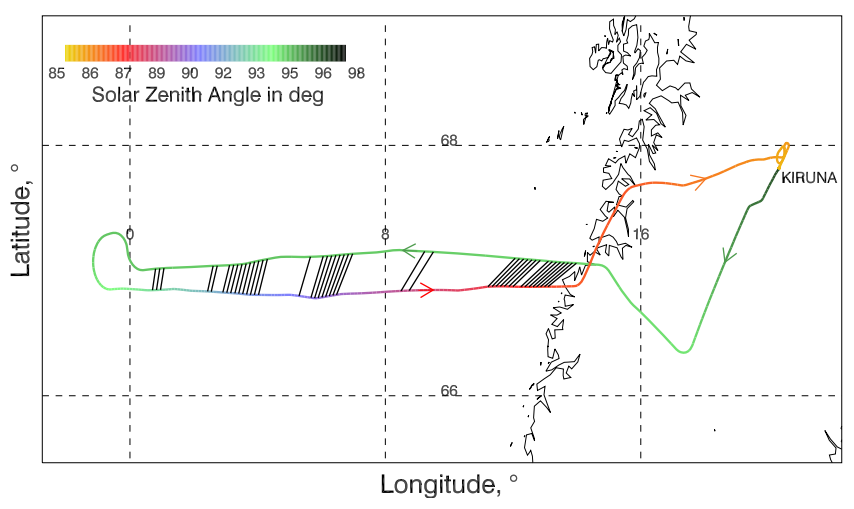

Fig. 3. Flight path of the RECONCILE self-match flight on 30 January 2010. The solar zenith angle on the track is represented by the colour scale. The black lines between outbound and inbound parts of the flight represent the trajectories of the match pairs fulfilling the strict match conditions (cf. Sect. 3.1).

tional analyses from the European Centre for Medium-Range Weather Forecasts (ECMWF).

\subsection{Measurements}

$\mathrm{ClO}$ was measured by the HALOX (HALogen OXide monitor) instrument situated in a pod underneath the left wing of the Geophysica aircraft (von Hobe et al., 2005). Through an inlet optimised for radical measurements, ambient air flows through two parallel measurement ducts where periodically ( 10 s cycles) $\mathrm{NO}$ is added, converting $\mathrm{ClO}$ to $\mathrm{Cl}$ atoms that are detected downstream by resonance fluorescence in the vacuum UV. HALOX has a detection limit of 5 ppt (parts per trillion by volume) and an accuracy of about $18 \%$. In our study, we investigate the temporal evolution of measurements of $[\mathrm{ClO}]$ for air masses sampled at different times. Therefore, most critical for the analysis presented below is precision, which varies between 4 and $8 \%$ depending on the stability of the light source (helium discharge lamps containing chlorine) and on the observed detector noise. Random noise is reduced and signal-to-noise-ratio increased by integrating the signal over six NO addition cycles, yielding a time resolution of $1 \mathrm{~min}$.

In the analysis below, we use the combined systematic (accuracy) and random (precision) error, and fully propagate this when calculating differences between data from the outbound and inbound flight legs. This is a conservative estimate, because some of the systematic errors will cancel out. However, there are parameters leading to such errors that can potentially change over the course of a flight (e.g. lamp output and contribution from different spectral lines), and the full consideration of all errors ensures the significance of our results.

Temperature and pressure were measured using commercial Rosemount sensors and geolocation data were provided by the Geophysica avionic system. 
To examine the accuracy of matches (cf. Sect. 3.1), we used measurements of nitrous oxide $\left(\mathrm{N}_{2} \mathrm{O}\right)$, which is expected to be unaffected by chemical processes on the time scale of the self-match flight and thus should show conserved mixing ratios. $\mathrm{N}_{2} \mathrm{O}$ was measured by the 2-channel gas chromatograph HAGAR (High Altitude Gas Analyser, Volk et al., 2000) with a time resolution of $90 \mathrm{~s}$. Mean precision and accuracy are better than 1 and $2 \%$ of the tropospheric background value, respectively.

Additionally, we used the data of COPAS (COndensation PArticle Counting System, Weigel et al., 2009) to identify exhaust particles from the Geophysica engines on the inbound flight leg. COPAS consists of an aerosol inlet and two dual-channel continuous flow Condensation Particle Counters (CPCs) and enables measurements of number concentrations of the particles with diameters of 6,11 and $15 \mathrm{~nm}$.

The presence and altitude of clouds were measured by the "Miniature aerosol lidar" instrument (MAL, Matthey et al., 2003). The ascent and descent data from modified Forward Scattering Spectrometer Probe (FSSP, with newer electronics; Dye and Baumgardner, 1984) and a Cloud Imaging Probe (CIP, Baumgardner et al., 2001) enabled parameterisation of the clouds layer below the flight track and thus estimation of the actinic flux.

\subsection{CLaMS simulations}

To define the match trajectories and to compare the $\mathrm{ClO}$ observations to values expected from various combinations of kinetic parameters, the chemistry-transport model CLaMS (McKenna et al., 2002a,b; Grooß et al., 2005) was used in a box model mode, with trajectory calculations based on ECMWF wind and temperature fields from operational analyses.

94 match trajectory start points on the outbound flight leg were defined according to the one-minute time intervals at which $\mathrm{ClO}$ was measured. Forward trajectories were calculated until 12:00 UTC of 30 January with 1 min time resolution. A point on the inbound flight leg matching a point on the outbound flight leg was chosen as the minimum distance between different forward trajectory points and the Geophysica position points at a given time.

Chemistry calculations were also carried out on these trajectories with various combinations of $J_{\mathrm{ClOOCl}}, k_{\mathrm{rec}}$ and $K_{\mathrm{eq}}$ values (cf. Sect. 3.4). For initialisation of the chemistry calculations, the Mainz 2-D model (Grooß et al., 1998) and trace gas mixing ratios measured on board Geophysica (for a full list of sampled species see von Hobe et al., 2012) during the outbound flight leg were used. Species not measured were taken from two-day back trajectory calculations initialised from a full hemispheric CLaMS simulation over the entire winter. The analysis of the backward trajectories revealed that the investigated air masses had been in darkness longer than $15 \mathrm{~h}$ prior to the flight, justifying the assumption of thermal equilibrium for the outbound flight leg (von Hobe et al.,
2005). During these $15 \mathrm{~h}$, temperature did not fall below $196.6 \mathrm{~K}$ on any of the trajectories, ruling out any significant contribution to $\mathrm{ClO}$ rise from $\mathrm{Cl}_{2}$ released during very recent heterogeneous activation.

\subsection{Investigated $\sigma_{\mathrm{ClOOCl}}$}

In the analysis we compare the measured increase in [ClO] with simulated increases resulting from $J_{\mathrm{ClOOCl}}$ based on the following four $\sigma_{\mathrm{ClOOCl}}$ data sets:

1. Pope et al. (2007) presented a $\mathrm{ClOOCl}$ spectrum giving the lowest absorption in the atmospherically relevant wavelength region (when scaled to any of the absorption peak cross sections plotted in Fig. 2) resulting in relatively small $J_{\mathrm{ClOOCl}}$ values. Pope et al. (2007) carried out an innovative experiment purifying $\mathrm{ClOOCl}$ prior to the absorption measurement, thus removing all impurities other than $\mathrm{Cl}_{2}$. However, in their spectral analysis they probably overcorrected for the $\mathrm{Cl}_{2}$ impurity as has been shown by von Hobe et al. (2009) (see below). The spectrum is scaled to measurements of Lien et al. (2009) to obtain cross sections.

2. von Hobe et al. (2009) used the technique proposed by Pope et al. (2007) to prepare and purify $\mathrm{ClOOCl}$, but measured the spectrum of a sample isolated in a neon matrix. In the atmospherically relevant region, their spectrum lies considerably higher than the Pope et al. (2007) spectrum but compares rather well to a Pope et al. (2007) gas phase spectrum uncorrected for $\mathrm{Cl}_{2}$. The von Hobe et al. (2009) spectrum is also scaled to cross section obtained by Lien et al. (2009).

3. Papanastasiou et al. (2009) measured absolute cross sections over a wavelength range from 220 to $420 \mathrm{~nm}$ and extrapolated their spectrum to $500 \mathrm{~nm}$. The new measurement improves an earlier study from the same laboratory (Burkholder et al., 1990). The two spectra have slightly different shapes but yield similar atmospheric $J_{\mathrm{ClOOCl}}$ values. The results presented by Burkholder et al. (1990) generally produced the best agreement in a number of studies comparing modelled and observed $\mathrm{ClO}_{\mathrm{x}}$ partitioning (Stimpfle et al., 2004; von Hobe et al., 2007; Schofield et al., 2008; Kremser et al., 2011) as well as ozone loss (Santee et al., 2003; Chipperfield et al., 2005; Frieler et al., 2006; Tripathi et al., 2006; von Hobe et al., 2007). Results of Papanastasiou et al. (2009) are recommended in JPL 2011 (Sander et al., 2011).

4. An artificial spectrum based on Papanastasiou et al. (2009), but with a simulated $\sigma_{\mathrm{ClOOCl}}$ set constant to $7.12 \times 10^{-21} \mathrm{~cm}^{2}$ molecule ${ }^{-1}$ between 420 and $500 \mathrm{~nm}$ is used to test the possible existence of an additional $\mathrm{ClOOCl}$ absorption band in the visible. The chosen 
value represents the absorption cross section at $420 \mathrm{~nm}$ measured by Papanastasiou et al. (2009).

\subsection{Estimation of the actinic flux}

To obtain the photolysis rate constant $J_{\mathrm{ClOOCl}}$ (Fig. 1c), the $\mathrm{ClOOCl}$ photolysis cross sections are multiplied by the spectrally resolved actinic flux (Eq. 2). To assess which of the photolysis cross sections described in Sect. 2.4 are realistic, it is crucial to minimise uncertainties in the actinic flux determined for the RECONCILE self-match flight. Below, we describe how the actinic fluxes were calculated, and test the sensitivity towards various atmospheric parameters.

Except for the CLaMS simulations presented in Sect. 3.4, where the radiative transfer code inherent in CLaMS (Lary and Pyle, 1991a,b; Becker et al., 2000) is used, actinic fluxes were calculated using the radiative transfer model MYSTIC (Monte Carlo code for the phYsically correct Tracing of photons in Cloudy atmospheres, Mayer, 2009). MYSTIC is operated as one of several solvers of the libRadtran radiative transfer package (Mayer and Kylling, 2005; see also http: //www.libradtran.org). For this study MYSTIC has been operated in fully spherical geometry (Emde and Mayer, 2007), which is essential for radiative transfer simulations during twilight. The ALIS (Absorption Lines Importance Sampling) method was also applied to perform the high spectral resolution calculations efficiently (Emde et al., 2011). When calculating the actinic fluxes and corresponding $J_{\mathrm{ClOOCl}}$ values, we define a "most realistic case" (MRC) and upper and lower sensitivity limits with respect to ozone, albedo, aerosol and clouds as described below. The results are shown in Fig. 4.

The MRC run was performed using Microwave Limb Sounder (MLS) ozone profiles from 30 January 2010 averaged for the area between 60 and $68^{\circ} \mathrm{N}$ and 0 and $20^{\circ} \mathrm{E}$. Sensitivity runs were carried out with the same profile scaled to 200 and $500 \mathrm{DU}$, respectively. While these values are unrealistically low and high, the results show that the sensitivity of the actinic flux towards ozone at zenith angles $>90^{\circ}$ is low in the relevant wavelength region (Fig. 4). Ozone absorption by the Hartley and Huggins bands in the UV extends to about $350 \mathrm{~nm}$, while absorption by the Chappuis bands in the visible only starts to become significant longwards of $450 \mathrm{~nm}$, giving rise to a spectral window with essentially no ozone absorption over a significant part of the $\mathrm{ClOOCl}$ spectrum.

The self-match portion of the flight was entirely over seawater. Ocean surface albedo depends on wavelength and solar zenith angle, and it is affected by atmospheric (wind speed, aerosol optical depth) and seawater parameters (phytoplankton biomass) and can take a rather broad range of values (Jin et al., 2004). A value of 0.1 was chosen for the MRC run, determined from lookup tables available at http://snowdog.larc.nasa.gov/jin/albedofind.html (Jin et al., 2004) choosing an aerosol optical depth (AOD) at $550 \mathrm{~nm}$ of 0.05 (cf. below), a surface wind speed of $16 \mathrm{~m} \mathrm{~s}^{-1}$ (acquired for the relevant time period from NOAA's National
Climatic Data Center, via their website http://www.ncdc. noaa.gov/oa/rsad/air-sea/seawinds.html) and a chlorophyll a concentration of $0.2 \mathrm{mg} \mathrm{m}^{-3}$ (estimated from SeaWIFS data for the relevant region and season using the Giovanni online data system developed and maintained by the NASA GES DISC, http://gdata1.sci.gsfc.nasa.gov/daac-bin/G3/gui. cgi?instance_id=ocean_month). Albedos of 0.05 and 0.8 were taken as lower and upper limits. Even for this wide range of albedos, the sensitivity is low at the zenith angles considered here. The sensitivity toward albedo shown in Fig. 4 is calculated for clear sky conditions, since cloud coverage would significantly reduce the albedo influence.

For aerosol scenarios, a default mixture for maritime clean aerosol adapted from the OPAC database (Hess et al., 1998; Emde et al., 2010) was used, with the AOD constantly adjusted to 0.06 for the MRC and to 0.11 for the upper limit sensitivity run. An aerosol free model atmosphere represented the lower sensitivity limit. A moderate sensitivity of the actinic flux calculated for the self-match flight towards these aerosol scenarios is observed at the highest solar zenith angles (Fig. 4). The different direction of the aerosol effect at the short and long wavelength ends in Fig. 4 at SZA $=93^{\circ}$ is explained by the different contributions of direct and diffuse radiation. The direct radiation dominates the total actinic flux above $450 \mathrm{~nm}$ and decreases with increasing AOD, as expected. The diffuse radiation increases with increasing AOD because more aerosol leads to more scattering. For $\lambda>450 \mathrm{~nm}$ the direct radiation dominates the total actinic flux and for $\lambda<450 \mathrm{~nm}$ the diffuse radiation dominates.

The downward looking lidar instrument MAL onboard the Geophysica indicated the presence of patchy clouds at altitudes up to $7 \mathrm{~km}$. MODIS (Moderate Resolution Imaging Spectroradiometer) satellite images (http://www.sat.dundee. ac.uk) show that this broken cloud layer extended over a rather large region around the flight track. For the radiative transfer model, two homogeneous cloud layers were included, at altitudes from 2 to $3 \mathrm{~km}$ and from 7 to $8 \mathrm{~km}$, respectively. Their optical properties were derived from FSSP and CIP measurements made on 2 February when a similar cloud situation existed. The clouds were pure ice clouds. The measured effective radius $\left(R_{\text {eff }}\right)$ of the lower cloud layer is $158 \mu \mathrm{m}$ and its ice water content (IWC) is $0.058 \mathrm{~g} \mathrm{~m}^{-3}$, for the upper cloud $R_{\text {eff }}=62 \mu \mathrm{m}$ and IWC $=0.012 \mathrm{~g} \mathrm{~m}^{-3}$ has been derived. For the radiative transfer simulations we assumed that the ice cloud particles are solid-columns and follow a gamma size distribution (HEY parameterisation, see libRadtran user's guide, based on Yang et al., 2000). Since the HEY parametrisations includes effective radii only up to $90 \mu \mathrm{m}$, we adapted the properties of the low cloud. The effective radius was set to $70 \mu \mathrm{m}$ and the ice water content was scaled to $0.026 \mathrm{~g} \mathrm{~m}^{-3}$ so that the cloud optical thickness corresponds exactly to the one that is derived from the measured values. Only the lower cloud layer was considered for the MRC, while a cloud free case and a case with both clouds mark the limits of the sensitivity runs. The clouds below 

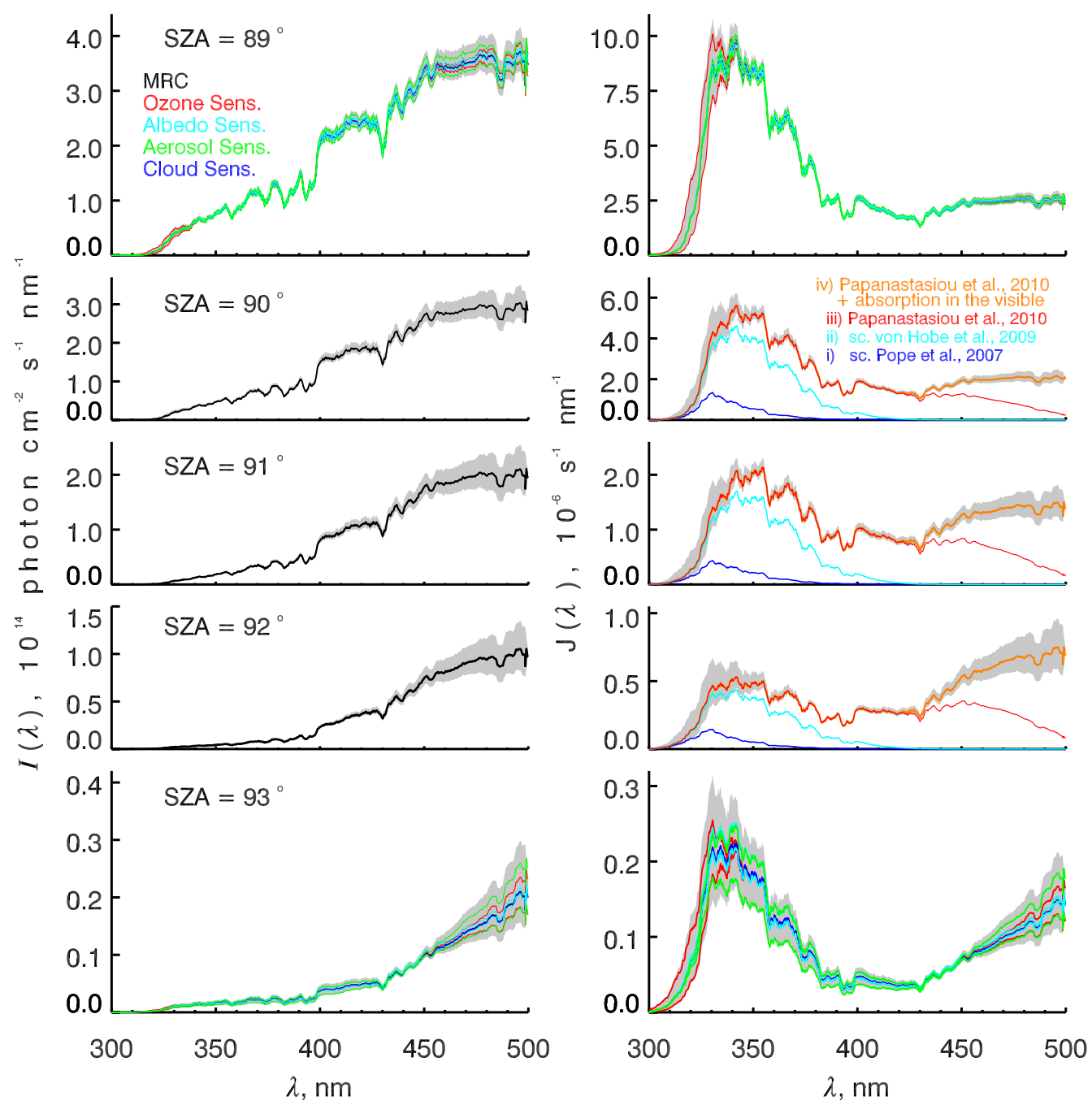

Fig. 4. Actinic fluxes and corresponding $J_{\mathrm{ClOOCl}}(\lambda)$ values with sensitivities for five different solar zenith angles. In the left panels, black lines represent the most realistic case of actinic flux and in right panels the lines correspond to $J_{\mathrm{ClOOCl}}(\lambda)$ based on various $\sigma_{\mathrm{ClOOCl}}$ cases. The grey areas in all panels show the maximum uncertainties from a total of 81 different scenarios with respect to ozone, albedo, aerosol and clouds. $J_{\mathrm{ClOOCl}}(\lambda)$ with uncertainty range is only shown for the Papanastasiou et al. (2009) cross sections extended into the visible where the sensitivity is the largest. For comparison, $J_{\mathrm{ClOOCl}}(\lambda)$ calculated with the other cross sections (same colours as in Fig. 1) for the MRC are shown in the $90^{\circ}, 91^{\circ}$ and $92^{\circ}$ SZA panels. For $89^{\circ}$ and $93^{\circ}$, the coloured lines show the individual sensitivities (all other parameters as in the MRC except for albedo, where the sensitivity is shown for a cloud free case) towards ozone (red), albedo (cyan), aerosol (green) and clouds (blue). See text in Sect. 2.5 for a description how these parameters were varied.

$7 \mathrm{~km}$ do not significantly affect the actinic flux at the altitude, zenith angles and wavelength relevant to this study (Fig. 4). The direct beam passes below $7 \mathrm{~km}$ only at $\mathrm{SZA}>93^{\circ}$. At this high SZA, its contribution to the total actinic flux at $18 \mathrm{~km}$ altitude is dominated by the diffuse contribution below $450 \mathrm{~nm}$.

To compare the $\mathrm{ClO}$ mixing ratios resulting from the considered $J_{\mathrm{ClOOCl}}$ values with $\mathrm{ClO}$ mixing ratios observed during the self-match flight, we use the overall $\mathrm{ClOOCl}$ photolysis rate constants effective in the atmosphere obtained by applying Eq. (2) with $I(\lambda)$ calculated for the MRC. The effective $J_{\mathrm{ClOOCl}}$ values with uncertainties resulting from the presented actinic flux investigation are plotted in Fig. 5 versus SZA. Clearly the differences resulting from the four different $\mathrm{ClOOCl}$ cross sections investigated in this study are greater than the uncertainty propagating from the actinic flux calculations.

\section{Results}

\subsection{Matches}

Match points on the inbound flight leg corresponding to those on the outbound leg were found by minimising the horizontal 


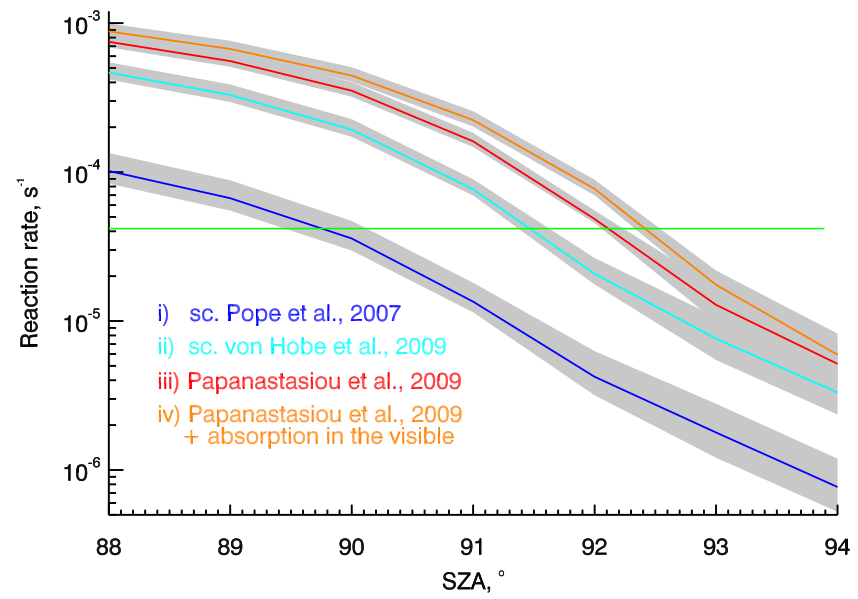

Fig. 5. Photolysis rate constants based on cross sections i-iv versus solar zenith angle. The green line shows the thermal dissociation rate $k_{\text {diss }}[\mathrm{M}]$ for comparison. $k_{\text {diss }}$ was determined from the recombination constant taken from JPL 2011 and the thermal equilibrium constant from Plenge et al. (2005). The number density [M] was calculated for the mean temperatures and pressure on the track of the Geophysica during the self-match flight. The grey areas show uncertainties in $J_{\mathrm{ClOOCl}}$ resulting from uncertainties in the actinic flux.

radius between the coordinates of the Geophysica track and the coordinates of the CLaMS forward trajectories at the corresponding time (cf. Sect. 2.3). The minimal radius between the Geophysica position and the match point calculated by CLaMS defines the match radius $R_{\text {match }}$. As shown in Fig. 6, $R_{\text {match }}$ was always smaller than $8.5 \mathrm{~km}$. To define a successful match pair, the vertical difference, in terms of potential temperature $(\Theta)$ was also considered. Here, we define $\Delta \Theta$ as a difference between $\Theta$ measured in the matching locations of observations on the out- and inbound flight legs and consider successful matches for $\Delta \Theta<2.0 \mathrm{~K}$. The vertical $\mathrm{ClO}$ gradient measured during descent was $15 \mathrm{ppt} \mathrm{K}^{-1}$ resulting in a $\mathrm{ClO}$ gradient smaller than the measurement uncertainty for a $2 \mathrm{~K}$ change in potential temperature.

Matches were validated using observations of the longlived tracer $\mathrm{N}_{2} \mathrm{O}$ by the HAGAR instrument. Match pairs, with differences between $\mathrm{N}_{2} \mathrm{O}$ measured on the outbound and inbound flight legs larger than the HAGAR precision for the relevant data points $(\sim 1.6$ part per billion by volume, $\mathrm{ppb}$ ), were rejected. With few exceptions, the tracer measurements confirm an excellent match performance (Fig. 6, lower panel), as do several encounters of the Geophysica exhaust on the inbound flight leg identified by COPAS observations.

41 out from 95 match pairs fulfilled all the conditions based on trajectory analysis and observed tracer concentrations. Those match pairs are marked by large black circles in Fig. 6.

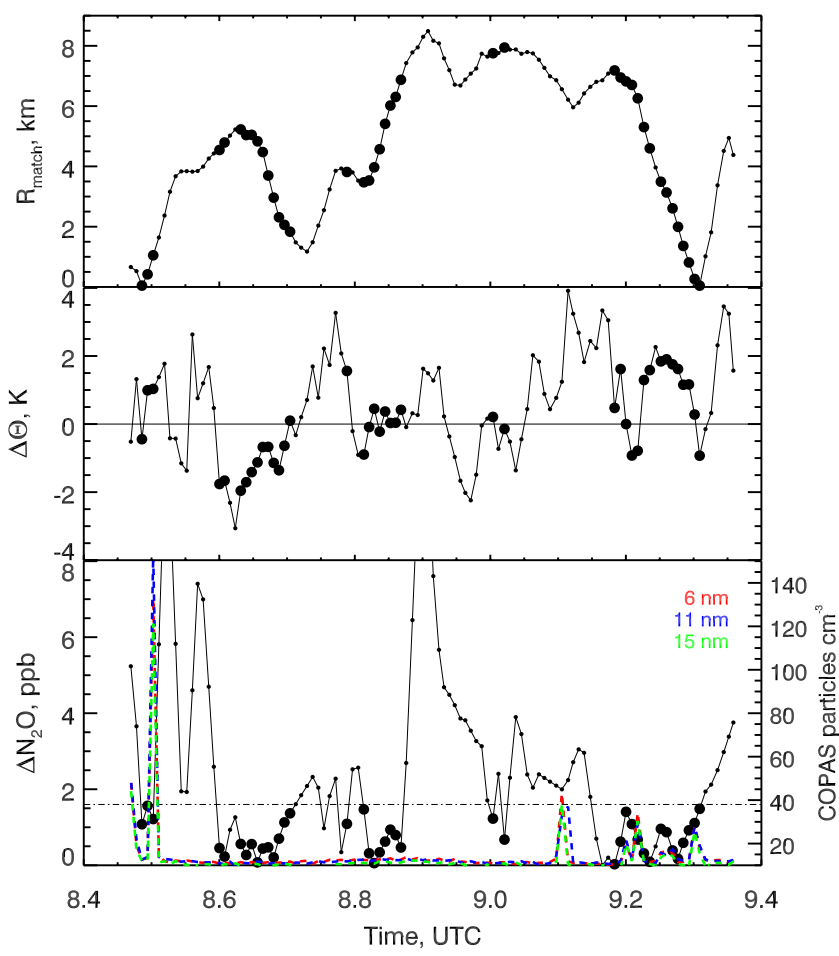

Fig. 6. Performance of the match-flight. The upper panel and the middle panel show the horizontal and the vertical match accuracy in terms of match radius $R_{\text {match }}$ (in $\mathrm{km}$ ) and potential temperature difference $\Delta \Theta$ (in $\mathrm{K})$, respectively. Differences in the mixing ratios of $\mathrm{N}_{2} \mathrm{O}$ are shown in the lower panel. The red, blue and green dashed lines correspond to the COPAS measurements. The increase of particle number concentrations indicates the Geophysica exhaust trail encounters. The large black circles show the 41 matches fulfilling the conditions described in Sect. 3.1.

\subsection{Night-time $\mathrm{ClO}_{\mathrm{x}}$ chemistry}

To estimate the $\mathrm{ClO}$ increase due to $\mathrm{ClOOCl}$ photolysis, the concentration of $\mathrm{ClOOCl}$ during the night was estimated using Eq. (1). Figure 7 shows $\mathrm{ClO}_{\mathrm{x}}$ mixing ratios calculated from the night-time HALOX $\mathrm{ClO}$ measurements and $K_{\text {eq }}$ published by Plenge et al. (2005), Ferracci and Rowley (2010) and $K_{\text {eq }}$ taken from JPL 2011 recommendation. An upper limit for $\mathrm{ClO}_{\mathrm{x}}$ is given by the total inorganic chlorine $\mathrm{Cl}_{\mathrm{y}}$, which was obtained from the tracer-tracer correlation with $\mathrm{N}_{2} \mathrm{O}$ valid for the year 2000 and published by Grooß et al. (2002). The $\mathrm{N}_{2} \mathrm{O}$ increase of $2.4 \%$ over the past $10 \mathrm{yr}$ was taken into account while no significant change in stratospheric $\mathrm{Cl}_{\mathrm{y}}$ was assumed.

$$
\begin{aligned}
\mathrm{Cl}_{\mathrm{y}}= & 3.394+0.001648 \cdot \mathrm{N}_{2} \mathrm{O}-7.659 \times 10^{-5} \cdot \mathrm{N}_{2} \mathrm{O}^{2} \\
& +2.646 \times 10^{-7} \cdot \mathrm{N}_{2} \mathrm{O}^{3}-4.469 \times 10^{-10} \cdot \mathrm{N}_{2} \mathrm{O}^{4}
\end{aligned}
$$

$\mathrm{N}_{2} \mathrm{O}$ and $\mathrm{Cl}_{\mathrm{y}}$ are given in ppb and the relation is valid for $\mathrm{N}_{2} \mathrm{O}$ values between $17-320 \mathrm{ppb}$. 


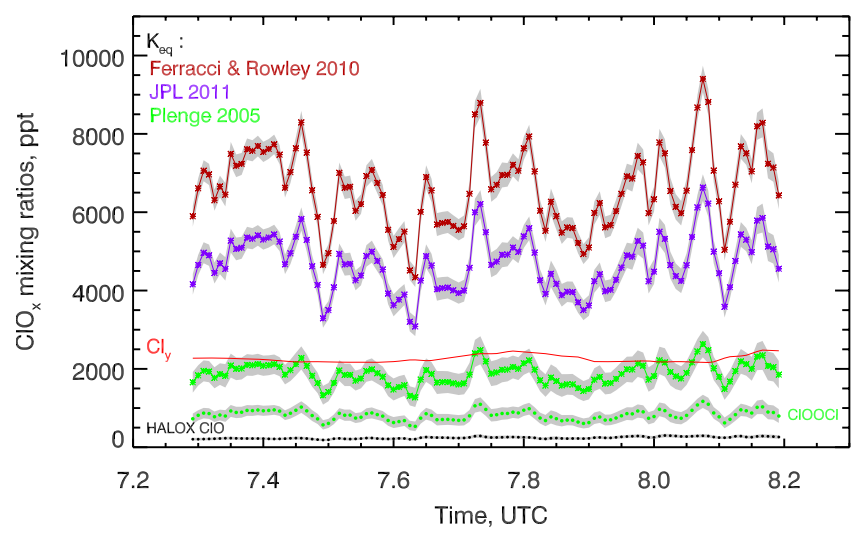

Fig. 7. $\mathrm{ClO}_{\mathrm{x}}$ mixing ratios derived from $\mathrm{HALOX} \mathrm{ClO}$ night measurements (black circles) in combination with three chosen $K_{\text {eq }}$. $\mathrm{ClOOCl}$ mixing ratios calculated with $\mathrm{HALOX} \mathrm{ClO}$ and $K_{\text {eq }}$ from Plenge et al. (2005) are represented by green circles. Grey areas show the uncertainties propagated from the HALOX ClO observations. The red line corresponds to $\mathrm{Cl}_{\mathrm{y}}$ calculated from the correlation with $\mathrm{N}_{2} \mathrm{O}$ (Eq. 3) measured by HAGAR.

For the observed night-time $\mathrm{ClO}$, only $K_{\text {eq }}$ from Plenge et al. (2005) seems plausible. $K_{\text {eq }}$ taken from studies of Ferracci and Rowley (2010) and JPL 2011 would result in $\mathrm{ClO}_{\mathrm{x}}$ exceeding $\mathrm{Cl}_{\mathrm{y}}$. Therefore, in our study, $K_{\text {eq }}$ from Plenge et al. (2005) is used to estimate $\mathrm{ClOOCl}$ (green circles in Fig. 7) for the further analysis.

\subsection{Constraints on $J_{\mathrm{ClOOCl}}$ from the observed increase in $\mathrm{ClO}$}

$J_{\mathrm{ClOOCl}}$ values presented in this section result from $\sigma_{\mathrm{ClOOCl}}$ i-iv and actinic flux $I(\lambda)$ calculated for the self-match flight (cf. Sect. 2.5). The overall rate of change in $\mathrm{ClO}$ concentration resulting from the reaction system (Reactions R1-R4) is given by:

$$
\begin{aligned}
0.5 \frac{\mathrm{d}[\mathrm{ClO}]}{\mathrm{d} t}= & J_{\mathrm{ClOOCl}}[\mathrm{ClOOCl}] \\
& +k_{\mathrm{diss}}[\mathrm{M}][\mathrm{ClOOCl}]-k_{\mathrm{rec}}[\mathrm{M}][\mathrm{ClO}]^{2}
\end{aligned}
$$

Figure 5 illustrates the SZA dependence of $J_{\mathrm{ClOOCl}}$ for the $\sigma_{\mathrm{ClOOCl}} \mathrm{i}-\mathrm{iv}$ for the conditions encountered during the RECONCILE self-match flight. The $\mathrm{ClOOCl}$ photolysis term is zero in darkness and rises more or less sharply, depending on the choice of $\sigma_{\mathrm{ClOOCl}}$, as SZA decreases. Also shown is the $\mathrm{ClOOCl}$ thermal decomposition rate constant $k_{\text {diss }}[\mathrm{M}]$ for the mean temperature and pressure observed during the flight. In thermal equilibrium, i.e. in dark conditions, the rate of $\mathrm{ClO}$ production from thermal decomposition of $\mathrm{ClOOCl}$ is expected to equal the removal rate via the $\mathrm{ClO}$ self-reaction, i.e. $k_{\text {diss }}[\mathrm{M}][\mathrm{ClOOCl}]=k_{\mathrm{rec}}[\mathrm{M}][\mathrm{ClO}]^{2}$ and $\mathrm{d}[\mathrm{ClO}] / \mathrm{d} t=0$. Thus, when the sun rises, $\mathrm{ClO}$ mixing ratios are expected to increase as soon as $J_{\mathrm{ClOOCl}}$ becomes large enough so that the photolysis reaction presents a significant additional $\mathrm{ClO}$

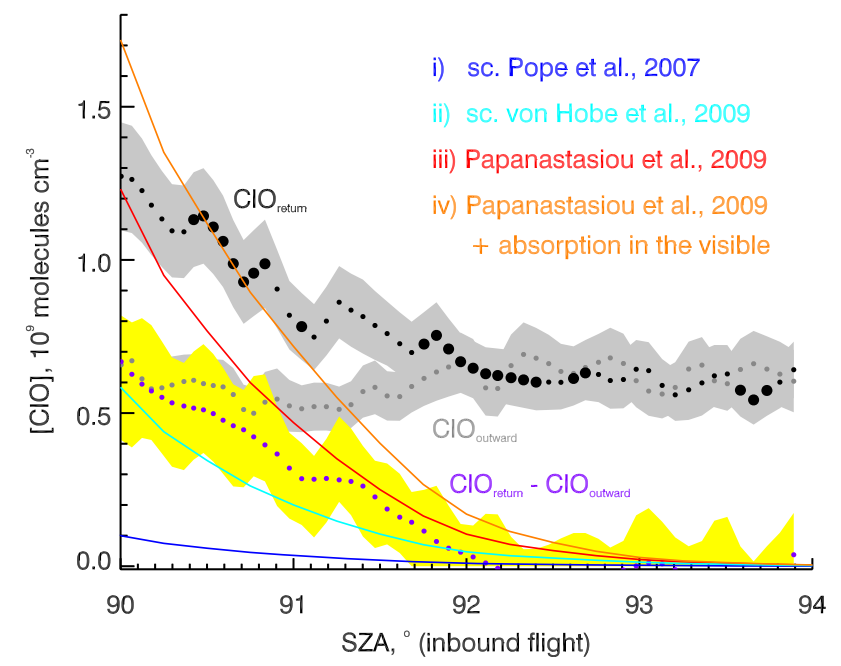

Fig. 8. Comparison of the observed rise of $\mathrm{ClO}$ concentrations (marked by the purple symbols) with SZA to the integrated $\mathrm{ClO}$ produced by simulations using photolysis rates $J_{\mathrm{ClOOCl}}$ based on i-iv (solid lines, cf. Sect. 2.4). The measured rise is calculated by subtraction of $\mathrm{ClO}$ measured on the outbound flight leg (grey symbols) from $\mathrm{ClO}$ measured on the inbound flight leg (shown as black symbols with the thicker ones representing strict match pairs). The outbound $\mathrm{ClO}$ data are plotted according to the SZA at the matching inbound measurements. Grey and yellow areas show the measurement uncertainties.

production term compared to the $\mathrm{ClOOCl}$ thermal decomposition. The photolysis becomes more significant than the decomposition at different SZA for the various $\sigma_{\mathrm{ClOOCl}}$ tested. These SZAs can be compared to the SZA, at which a significant rise of $\mathrm{ClO}$ concentration is actually observed.

Figure 8 shows that observed [ClO] starts to rise close to a SZA of $92^{\circ}$. Also shown is the rise in $[\mathrm{ClO}]$ expected for the four different photolysis rate constants $\mathrm{i}-\mathrm{iv}$. It was calculated using

$\Delta[\mathrm{ClO}]=2 \times \int_{t\left(95^{\circ}\right)}^{t(\mathrm{SZA})} J_{\mathrm{ClOOCl}} \cdot[\mathrm{ClOOCl}]_{\mathrm{outward}} \cdot \mathrm{d} t$

under the assumption that $\mathrm{ClO}$ removal from the self-reaction (R1) is negligible. Strictly, this assumption holds true only at sunrise, i.e. when the first $\mathrm{ClOOCl}$ molecule is photolysed. $[\mathrm{ClOOCl}]_{\text {outward }}$ was calculated from observed night-time [ClO] and $K_{\text {eq }}$ according to Plenge et al. (2005) (cf. Sect. 3.2 and Fig. 7). As SZA decreases, [ClOOCl] will become smaller and $\mathrm{ClO}$ removal via the self-reaction faster, both leading to a reduced overall rate of $[\mathrm{ClO}]$ increase. Thus, at the threshold SZA (Fig. 5), the observed [ClO] is expected to start rising simultaneously with the integrated simulated [ClO] from $\mathrm{ClOOCl}$ photolysis and then falling more and more below the calculated $[\mathrm{ClO}]$ rise as SZA decreases.

For Pope et al. (2007) cross sections (i), [ClO] starts to increase much later and rises much slower than observed $[\mathrm{ClO}]$. On the other hand, a significant $\mathrm{ClOOCl}$ absorption 


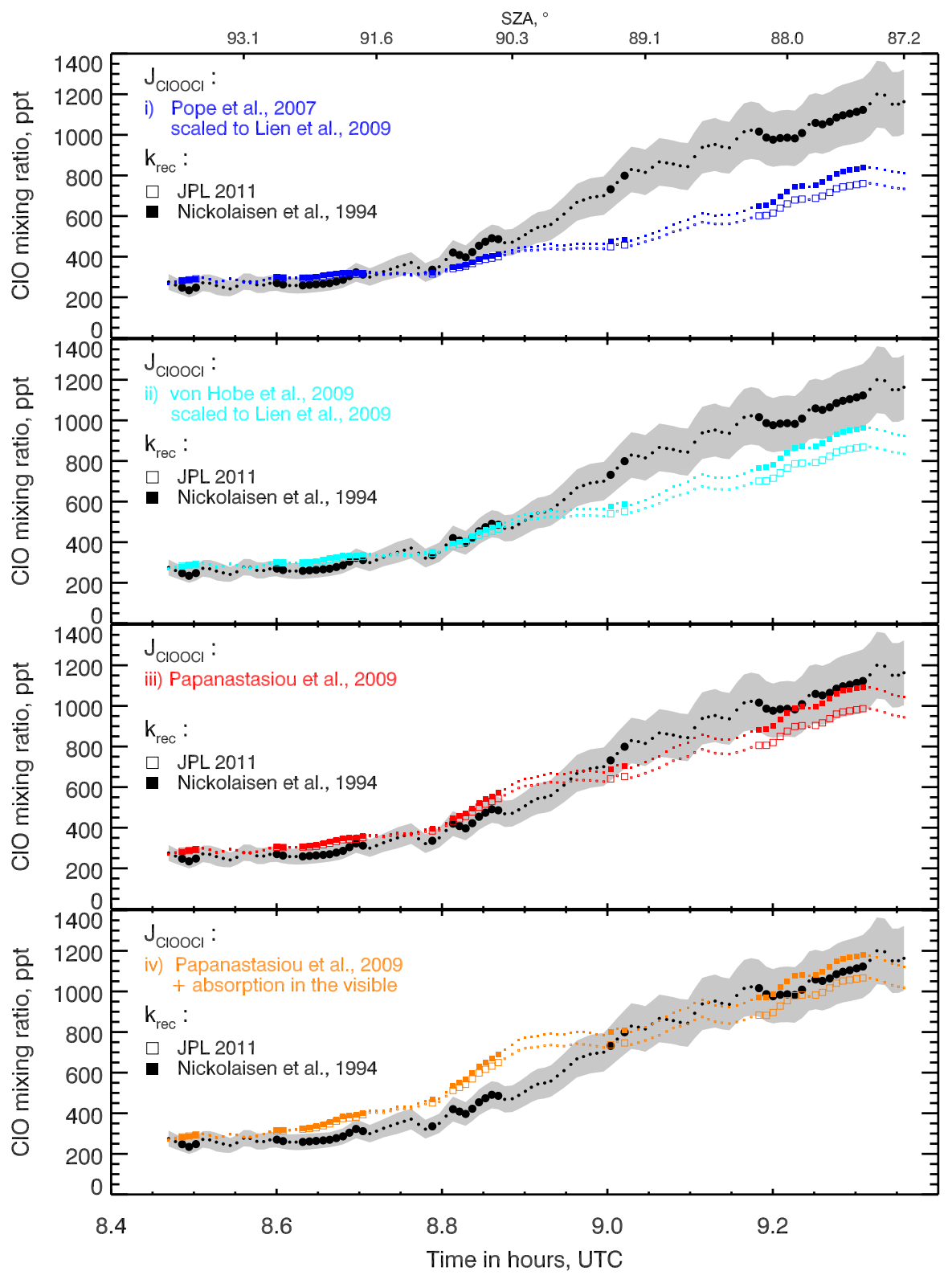

Fig. 9. Comparison of HALOX ClO mixing ratios (black points with grey uncertainty areas) with the results of CLaMS simulations using various combinations of kinetic parameters. The "good matches" are marked by large symbols.

band in the visible (case iv) would lead to an even earlier increase in $[\mathrm{ClO}]$ and is not supported by our observations. $J_{\mathrm{ClOOCl}}$ values based on the scaled spectrum of von Hobe et al. (2009) (ii) and cross sections of Papanastasiou et al. (2009) (iii) produce a reasonably good agreement between observed and expected $[\mathrm{ClO}]$ rise within the given uncertainties. They can probably be regarded as maximum and minimum of plausible photolysis cross sections effective in the atmosphere.

\subsection{Chemistry simulations along match trajectories}

In this analysis, box model runs with full chemistry calculations are initialised with the species taken from the Mainz 2-
D model and measurements made on the outbound flight leg (von Hobe et al., 2012). For calculation of $\mathrm{ClOOCl}$ mixing ratios, HALOX $\mathrm{ClO}$ and $K_{\text {eq }}$ from the publication of Plenge et al. (2005) are used (cf. Sect. 3.2). The ClO mixing ratios resulting from the chemistry simulations along the trajectories between the points on the outbound and the inbound flight leg are compared with values observed on the inbound flight leg. The results are shown in Fig. 9.

Simulations were carried out for combinations of the four $J_{\mathrm{ClOOCl}}$ parameterisations discussed above and two parameterisations of $k_{\text {rec }}$ : JPL 2011 and Nickolaisen et al. (1994). JPL $2011 k_{\text {rec }}$ was chosen as the current recommendation to 
the scientific community, whereas $k_{\text {rec }}$ published by Nickolaisen et al. (1994) due to its good agreement with both atmospheric observations and unimolecular theory as shown by von Hobe et al. (2007).

Irrespective of the agreement between modelled and observed $\mathrm{ClO}$, Fig. 9 illustrates the point made earlier, that immediately after sunrise, at $\mathrm{SZA}>90^{\circ}, \mathrm{ClO}$ mixing ratios are much more sensitive to $J_{\mathrm{ClOOCl}}$ than to $k_{\text {rec }}$. Clearly, at high SZA at sunrise, the steady state approximation $J_{\mathrm{ClOOCl}} / k_{\mathrm{rec}} \approx[\mathrm{ClO}]^{2} /[\mathrm{ClOOCl}]$ is not valid. Only as the sun rises higher and $\mathrm{ClO}$ builds up, the influence of $k_{\text {rec }}$ becomes important.

In agreement with the results presented in Sect. 3.3, for the scaled spectrum of Pope et al. (2007), simulated ClO falls below observed mixing ratios as soon as they start to rise. In case (ii), the model consistently follows the observations at very high SZA over sunrise, but predicts significantly smaller $\mathrm{ClO}$ mixing ratios than observed as SZA decreases further and photochemical steady state is approached. At $\mathrm{SZA}>89^{\circ}$, simulations (iii) and (iv) show the best agreement with the observations. Here, the use of $k_{\text {rec }}$ from JPL 2011 would even allow for higher cross sections than the Papanastasiou et al. (2009) results. However, both overestimate $\mathrm{ClO}$ at higher zenith angles, especially cross section (iv) with the artificial absorption band in the visible.

Provided that there are no additional reactions other than (Reactions R1-R4) governing the $\mathrm{ClO}$ dimer cycle, the differences between model and observations for cases (i) and (iv) are too large for the underlying cross sections to be realistic in the atmosphere. For cases (ii) and (iii), the behaviour of the scaled von Hobe et al. (2009) parameterisation underestimating observed $\mathrm{ClO}$ at $\mathrm{SZA}<90^{\circ}$ and Papanastasiou et al. (2009) overestimating $\mathrm{ClO}$ at $\mathrm{SZA}>90^{\circ}$, suggests $\mathrm{ClOOCl}$ cross sections within the range between those two. The HALOX measurements indicate an SZA threshold of significant $\mathrm{ClO}$ increase due to $\mathrm{ClOOCl}$ photolysis near $92^{\circ}$ (cf. Fig. 8).

\section{Conclusions}

$\mathrm{ClO}$ measurements during the RECONCILE self-match flight on 30 January 2010 were used to examine the plausibility of published $\mathrm{ClOOCl}$ absorption cross sections measured in the laboratory and to test the hypothesis of an additional $\mathrm{ClOOCl}$ absorption in the visible. The analysis of the increase in $\mathrm{ClO}$ concentration over sunrise as well as CLaMS chemistry simulations suggest $J_{\mathrm{ClOOCl}}$ in the range resulting from absorption cross sections published by Papanastasiou et al. (2009) and a spectrum from von Hobe et al. (2009) scaled to Lien et al. (2009). The spectrum published by Pope et al. (2007) and scaled to Lien et al. (2009) is clearly inconsistent with our observations unless there are additional unknown processes converting $\mathrm{ClOOCl}$ to $\mathrm{ClO}$ in the atmosphere. The observed behaviour of $\mathrm{ClO}$ mixing ratios starting to increase at SZA below $92^{\circ}$ is also not consistent with an additional absorption band of $\mathrm{ClOOCl}$ at wavelengths $>420 \mathrm{~nm}$. Our results agree with the studies of Stimpfle et al. (2004); von Hobe et al. (2007); Schofield et al. (2008); Kremser et al. (2011), but are fully independent of $k_{\text {rec }}$ at the highest zenith angles above $91^{\circ}$. The range of possible $J_{\mathrm{ClOOCl}}$ estimated within our analysis coincides with $J_{\mathrm{ClOOCl}}$ used by Santee et al. (2003); Chipperfield et al. (2005); Frieler et al. (2006); Tripathi et al. (2006); von Hobe et al. (2007) for the ozone loss analysis and would also reproduce the observations.

$J_{\mathrm{ClOOCl}}$ is strongly dependent on actinic flux $I(\lambda)$, which at a defined time and location varies due to ozone, albedo, clouds and aerosol. The sensitivity studies showed that albedo as well as tropospheric clouds do not influence $I(\lambda)$ and thus $J_{\mathrm{ClOOCl}}$ significantly. $I(\lambda)$ is moderately sensitive to ozone, particularly at high solar zenith angles and some more sensitive to aerosol loading. The uncertainties in $I(\lambda)$ propagate into $J_{\mathrm{ClOOCl}}$, but are smaller than the differences between $J_{\mathrm{ClOOCl}}$ based on different $\sigma_{\mathrm{ClOOCl}}$.

Additionally, the analysis of night-time $\mathrm{ClO}$ indicates that our observations are inconsistent with equilibrium constants higher than $K_{\text {eq }}$ published by Plenge et al. (2005).

Acknowledgements. The authors thank the M-55 Geophysica team and the MDB (Myasishchev Design Bureau, Moscow, Russia) for planning and carrying out the flights and Enviscope GmbH for logistical support during the RECONCILE campaign. We are also grateful to the mission scientist H. Schlager (DLR Oberpfaffenhofen) for organisation and flight planning and to ECMWF for providing the meteorological analysis. We thank Bernhard Mayer and Arve Kylling for their valuable support with the LibRadTran model runs.

The RECONCILE project is funded under the European Commission Seventh Framework Programme (FP7) under the Grant number RECONCILE-226365-FP7-ENV-2008-1. The Ph.D. student position of Olga Sumińska-Ebersoldt is financed within the ENVIVAL-LIFE project through a grant from Bundesministerium für Wirtschaft (BMWi) via DLR, Germany.

Edited by: F. Khosrawi

\section{References}

Baumgardner, D., Jonsson, H., Dawson, W., O'Connor, D., and Newton, R.: The cloud, aerosol and precipitation spectrometer: a new instrument for cloud investigations, Atmos. Res., 59-60, 251-264, doi:10.1016/S0169-8095(01)00119-3, 2001.

Becker, G., Grooß, J. U., McKenna, D. S., and Müller, R.: Stratospheric photolysis frequencies: Impact of an improved numerical solution of the radiative transfer equation, J. Atmos. Chem., 37, 217-229, 2000.

Birk, M., Friedl, R. R., Cohen, E. A., Pickett, H. M., and Sander, S. P.: The Rotational Spectrum and Structure of Chlorine Peroxide, J. Chem. Phys., 91, 6588-6597, doi:10.1063/1.457377, 1989.

Bloss, W. J., Nickolaisen, S. L., Salawitch, R. J., Friedl, R. R., and Sander, S. P.: Kinetics of the $\mathrm{ClO}$ self-reaction and $210 \mathrm{~nm}$ 
absorption cross section of the $\mathrm{ClO}$ dimer, J. Phys. Chem. A, 105, 11226-11239, doi:10.1021/jp012429y, 2001.

Burkholder, J. B., Orlando, J. J., and Howard, C. J.: UltravioletAbsorption Cross-Sections of $\mathrm{Cl}_{2} \mathrm{O}_{2}$ Between 210 and $410 \mathrm{~nm}$, J. Phys. Chem., 94, 687-695, doi:10.1021/j100365a033, 1990.

Chen, H. Y., Lien, C. Y., Lin, W. Y., Lee, Y. T., and Lin, J. J.: UV Absorption Cross Sections of $\mathrm{ClOOCl}$ are Consistent with Ozone Degradation Models, Science, 324, 781-784, doi:10.1126/science.1171305, 2009.

Chipperfield, M. P., Feng, W., and Rex, M.: Arctic ozone loss and climate sensitivity: Updated three-dimensional model study, Geophys. Res. Lett., 32, L11813, doi:10.1029/2005GL022674, 2005.

Cox, R. A. and Hayman, G. D.: The Stability and Photochemistry of Dimers of the ClO Radical and Implications for Antarctic Ozone Depletion, Nature, 332, 796-800, doi:10.1038/332796a0, 1988.

DeMore, W. B. and Tschuikow-Roux, E.: Ultraviolet Spectrum and Chemical Reactivity of the ClO Dimer, J. Phys. Chem., 94, 5856-5860, doi:10.1021/j100378a046, 1990.

Drdla, K. and Müller, R.: Temperature thresholds for polar stratospheric ozone loss, Atmos. Chem. Phys. Discuss., 10, $28687-$ 28720, doi:10.5194/acpd-10-28687-2010, 2010.

Dye, J. E. and Baumgardner, D.: Evaluation of the Forward Scattering Spectrometer Probe. Part I: Electronic and Optical Studies, J. Atmos. Ocean. Tech., 1, 329-344, doi:10.1175/15200426(1984)001<0329:EOTFSS > 2.0.CO;2, 1984.

Emde, C. and Mayer, B.: Simulation of solar radiation during a total eclipse: a challenge for radiative transfer, Atmos. Chem. Phys., 7, 2259-2270, doi:10.5194/acp-7-2259-2007, 2007.

Emde, C., Buras, R., Mayer, B., and Blumthaler, M.: The impact of aerosols on polarized sky radiance: model development, validation, and applications, Atmos. Chem. Phys., 10, 383-396, doi:10.5194/acp-10-383-2010, 2010.

Emde, C., Buras, R., and Mayer, B.: ALIS: An efficient method to compute high spectral resolution polarized solar radiances using the Monte Carlo approach, J. Quant. Spectrosc. Ra., 112, 16221631, doi:10.1016/j.jqsrt.2011.03.018, 2011.

Ferracci, V. and Rowley, M.: Kinetic and thermochemical studies of the $\mathrm{ClO}+\mathrm{ClO}+\mathrm{M} \rightleftarrows \mathrm{Cl}_{2} \mathrm{O}_{2}+\mathrm{M}$ reaction, Phys. Chem. Chem. Phys., 12, 11596-11608, doi:10.1039/C0CP00308E, 2010.

Frieler, K., Rex, M., Salawitch, R. J., Canty, T., Streibel, M., Stimpfle, R. M., Pfeilsticker, K., Dorf, M., Weisenstein, D. K., and Godin-Beekmann, S.: Toward a better quantitative understanding of polar stratospheric ozone loss, Geophys. Res. Lett., 33, L10812, doi:10.1029/2005GL025466, 2006.

Grooß, J.-U., Brühl, C., and Peter, T.: Impact of aircraft emissions on tropospheric and stratospheric ozone. Part I: chemistry and 2-D model results, Atmos. Environ., 32, 3173-3184, doi:10.1016/S1352-2310(98)00016-8, 1998.

Grooß, J.-U., Günther, G., Konopka, P., Müller, R., McKenna, D. S., Stroh, F., Vogel, B., Engel, A., Müller, M., Hoppel, K., Bevilacqua, R., Richard, E., Webster, C. R., Elkins, J. W., Hurst, D. F., Romashkin, P. A., and Baumgardner, D. G.: Simulation of ozone depletion in spring 2000 with the Chemical Lagrangian Model of the Stratosphere (CLaMS), J. Geophys. Res.-Atmos., 107, 8295, doi:10.1029/2001JD000456, 2002.

Grooß, J.-U., Günther, G., Müller, R., Konopka, P., Bausch, S., Schlager, H., Voigt, C., Volk, C.M., and Toon, G. C.: Simulation of denitrification and ozone loss for the Arctic winter 2002/2003,
Atmos. Chem. Phys., 5, 1437-1448, doi:10.5194/acp-5-14372005, 2005.

Hess, M., Koepke, P., and Schult, I.: Optical Properties of Aerosols and Clouds: The Software Package OPAC, B. Am. Meteorol. Soc., 79, 831-844, doi:10.1175/15200477(1998)079<0831:OPOAAC>2.0.CO;2, 1998.

Huang, W.-T., Chen, A. F., Chen, I.-C., Tsai, C.-H., and Lin, J. J.-M.: Photodissociation dynamics of $\mathrm{ClOOCl}$ at 248.4 and $308.4 \mathrm{~nm}$, Phys. Chem. Chem. Phys., 13, 8195-8203, doi:10.1039/C0CP02453H, 2011.

Huder, K. J. and DeMore, W. B.: Absorption Cross Sections of the ClO Dimer, J. Phys. Chem., 99, 3905-3908, doi:10.1021/j100012a007, 1995.

Jin, B., Chen, I. C., Huang, W. T., Lien, C. Y., Guchhait, N., and Lin, J. J.: Photodissociation Cross Section of $\mathrm{ClOOCl}$ at $330 \mathrm{~nm}$, J. Phys. Chem. A, 114, 4791-4797, doi:10.1021/jp909374k, 2010.

Jin, Z., Charlock, T. P., Smith, W. L. J., and Rutledge, K.: A parameterization of ocean surface albedo, Geophys. Res. Lett., 31, L22301, doi:10.1029/2004GL021180, 2004.

Kaledin, A. L. and Morokuma, K.: An ab initio direct-trajectory study of the photodissociation of $\mathrm{ClOOCl}$, J. Chem. Phys., 113, 5750-5762, doi:10.1063/1.1290606, 2000.

Kawa, S. R., Stolarski, R. S., Newman, P. A., Douglass, A. R., Rex, M., Hofmann, D. J., Santee, M. L., and Frieler, K.: Sensitivity of polar stratospheric ozone loss to uncertainties in chemical reaction kinetics, Atmos. Chem. Phys., 9, 8651-8660, doi:10.5194/acp-9-8651-2009, 2009.

Kremser, S., Schofield, R., Bodeker, G. E., Connor, B. J., Rex, M., Barret, J., Mooney, T., Salawitch, R. J., Canty, T., Frieler, K., Chipperfield, M. P., Langematz, U., and Feng, W.: Retrievals of chlorine chemistry kinetic parameters from Antarctic $\mathrm{ClO}$ microwave radiometer measurements, Atmos. Chem. Phys., 11, 5183-5193, doi:10.5194/acp-11-5183-2011, 2011.

Lary, D. J. and Pyle, J. A.: Diffuse radiation, twilight, and photochemistry - I, J. Atmos. Chem., 13, 373-392, doi:10.1007/BF00057753, 1991a.

Lary, D. J. and Pyle, J. A.: Diffuse radiation, twilight, and photochemistry - II, J. Atmos. Chem., 13, 393-406, doi:10.1007/BF00057754, 1991b.

Lien, C. Y., Lin, W. Y., Chen, H. Y., Huang, W. T., Jin, B., Chen, I. C., and Lin, J. J.: Photodissociation cross sections of $\mathrm{ClOOCl}$ at 248.4 and $266 \mathrm{~nm}$, J. Chem. Phys., 131, 174301, doi:10.1063/1.3257682, 2009.

Matthey, R., Cacciani, M., Fiocco, G., Martinez, A. A., Martucci, G., Mitev, V., Pace, G., and Stefanutti, L.: Observations of aerosol and clouds with the ABLE and MAL lidars during the mid-latitude and Arctic ENVISAT validation campaigns, in: European Rocket and Balloon Programmes and Related Research, edited by: Warmbein, B., Vol. 530 of ESA Special Publication, 579-584, 2003.

Mayer, B.: Radiative transfer in the cloudy atmosphere, European Physical Journal Conferences, 75-99, doi:10.1140/epjconf/e2009-00912-1, 2009.

Mayer, B. and Kylling, A.: Technical note: The libRadtran software package for radiative transfer calculations - description and examples of use, Atmos. Chem. Phys., 5, 1855-1877, doi:10.5194/acp-5-1855-2005, 2005.

McElroy, M. B., Salawitch, R. J., Wofsy, S. C., and Logan, J. A.: Reductions Of Antarctic Ozone Due To Synergistic 
Interactions Of Chlorine And Bromine, Nature, 321, 759-762, doi:10.1038/321759a0, 1986.

McKenna, D. S., Grooß, J. U., Günther, G., Konopka, P., Müller, R., Carver, G., and Sasano, Y.: A new Chemical Lagrangian Model of the Stratosphere (CLaMS) - 2. Formulation of chemistry scheme and initialization, J. Geophys. Res.-Atmos., 107, 4256, doi:10.1029/2000JD000114, 2002a.

McKenna, D. S., Konopka, P., Grooß, J. U., Günther, G., Müller, R., Spang, R., Offermann, D., and Orsolini, Y.: A new Chemical Lagrangian Model of the Stratosphere (CLaMS) - 1. Formulation of advection and mixing, J. Geophys. Res.-Atmos., 107, 4309, doi:10.1029/2000JD000113, 2002b.

Molina, L. T. and Molina, M. J.: Production of $\mathrm{Cl}_{2} \mathrm{O}_{2}$ from the Self-Reaction of the ClO Radical, J. Phys. Chem., 91, 433-436, 1987.

Moore, T. A., Okumura, M., Seale, J. W., and Minton, T. K.: UV Photolysis of ClOOCl, J. Phys. Chem. A, 103, 1691-1695, doi:10.1021/jp984410+, 1999.

Nickolaisen, S. L., Friedl, R. R., and Sander, S. P.: Kinetics And Mechanism Of The $\mathrm{ClO}+\mathrm{ClO}$ Reaction - Pressure And Temperature Dependences Of The Bimolecular And Termolecular Channels And Thermal-Decomposition Of Chlorine Peroxide, J. Phys. Chem., 98, 155-169, doi:10.1021/j100052a027, 1994.

Papanastasiou, D. K., Papadimitriou, V. C., Fahey, D. W., and Burkholder, J. B.: UV Absorption Spectrum of the ClO Dimer $\left(\mathrm{Cl}_{2} \mathrm{O}_{2}\right)$ between 200 and $420 \mathrm{~nm}$, J. Phys. Chem. A, 113, 13711-13726, doi:10.1021/jp9065345, 2009.

Peterson, K. A. and Francisco, J. S.: Does chlorine peroxide absorb below $250 \mathrm{~nm}$ ?, J. Chem. Phys., 121, 2611-2616, doi:10.1063/1.1766012, 2004.

Plenge, J., Kuhl, S., Vogel, B., Müller, R., Stroh, F., von Hobe, M., Flesch, R., and Ruhl, E.: Bond strength of chlorine peroxide, J. Phys. Chem. A, 109, 6730-6734, doi:10.1021/jp044142h, 2005.

Pope, F. D., Hansen, J. C., Bayes, K. D., Friedl, R. R., and Sander, S. P.: Ultraviolet absorption spectrum of chlorine peroxide, $\mathrm{ClOOCl}$, J. Phys. Chem. A, 111, 4322-4332, doi:10.1021/jp067660w, 2007.

Sander, S. P., Friedl, R. R., Golden, D. M., Kurylo, M. J., Moortgat, G. K., Wine, P. H., Ravishankara, A. R., Kolb, C. E., Molina, M. J., Finlayson-Pitts, B. J., Huie, R. E., and Orkin, V. L.: Chemical kinetics and photochemical data for use in atmospheric studies Evaluation Number 15, Jet Propulsion Laboratory, Pasadena, CA, 2006.

Sander, S. P., Friedl, R. R., Barker, J. R., Golden, D. M., Kurylo, M. J., Wine, P. H., Abbatt, J., Burkholder, J. B., Kolb, C. E., Moortgat, G. K., Huie, R. E., and Orkin, V. L.: Chemical kinetics and photochemical data for use in atmospheric studies Evaluation Number 17, Jet Propulsion Laboratory, Pasadena, CA, 2011.

Santee, M. L., Manney, G. L., Waters, J. W., and Livesey, N. J.: Variations and climatology of $\mathrm{ClO}$ in the polar lower stratosphere from UARS Microwave Limb Sounder measurements, J. Geophys. Res.-Atmos., 108, 4454-4454, doi:10.1029/2002JD003335, 2003.

Schofield, R., Frieler, K., Wohltmann, I., Rex, M., von Hobe, M., Stroh, F., Koch, G., Peter, T., Canty, T., Salawitch, R., and Volk, C. M.: Polar stratospheric chlorine kinetics from a selfmatch flight during SOLVE-II/EUPLEX, Geophys. Res. Lett., 35, L01807, doi:10.1029/2007GL031740, 2008.
Solomon, S., Garcia, R. R., Rowland, F. S., and Wuebbles, D.: On the Depletion of Antarctic Ozone, Nature, 321, 755-758, doi:10.1038/321755a0, 1986.

Stimpfle, R. M., Wilmouth, D. M., Salawitch, R. J., and Anderson, J. G.: First measurements of $\mathrm{ClOOCl}$ in the stratosphere: The coupling of $\mathrm{ClOOCl}$ and $\mathrm{ClO}$ in the Arctic polar vortex, J. Geophys. Res.-Atmos., 109, D03301, doi:10.1029/2003JD003811, 2004.

Toniolo, A., Granucci, G., Inglese, S., and Persico, M.: Theoretical study of the photodissociation dynamics of $\mathrm{ClOOCl}$, Phys. Chem. Chem. Phys., 3, 4266-4279, doi:10.1039/b104044h, 2001.

Tripathi, O. P., Godin-Beekmann, S., Lefevre, F., Marchand, M., Pazmino, A., Hauchecorne, A., Goutail, F., Schlager, H., Volk, C. M., Johnson, B., Konig-Langlo, G., Balestri, S., Stroh, F., Bui, T. P., Jost, H. J., Deshler, T., and von der Gathen, P.: High resolution simulation of recent Arctic and Antarctic stratospheric chemical ozone loss compared to observations, J. Atmos. Chem. 55, 205-226, doi:10.1007/s10874-006-9028-8, 2006.

Volk, C., Riediger, O., Strunk, M., Schmidt, U., Ravegnani, F., Ulanovsky, A., and Rudakovand, V.: In situ Tracer Measurements in the Tropical Tropopause Region During APETHESEO, Eur. Comm. Air Pollut. Res. Report 73, 661-664, 2000.

von Hobe, M.: Revisiting Ozone Depletion, Science, 318, 1878, doi:10.1126/science.1151597, 2007.

von Hobe, M., Grooß, J.-U., Müller, R., Hrechanyy, S., Winkler, U., and Stroh, F.: A re-evaluation of the $\mathrm{ClO} / \mathrm{Cl}_{2} \mathrm{O}_{2}$ equilibrium constant based on stratospheric in-situ observations, Atmos. Chem. Phys., 5, 693-702, doi:10.5194/acp-5-693-2005, 2005.

von Hobe, M., Salawitch, R. J., Canty, T., Keller-Rudek, H., Moortgat, G. K., Grooß, J.-U., Müller, R., and Stroh, F.: Understanding the kinetics of the $\mathrm{ClO}$ dimer cycle, Atmos. Chem. Phys., 7, 3055-3069, doi:10.5194/acp-7-3055-2007, 2007.

von Hobe, M., Stroh, F., Beckers, H., Benter, T., and Willner, H.: The UV/Vis absorption spectrum of matrix-isolated dichlorine peroxide, ClOOCl, Phys. Chem. Chem. Phys., 11, 1571-1580, doi:10.1039/B814373K, 2009.

von Hobe, M., Grooß, J.-U., Pope, F., Peter, T., Cairo, F., Orsolini, I., Volk, C., Marchand, M., Janosi, I., Schlager, H., Stroh, F., Rex, M., Wienhold, F., and RECONCILE-Team: Reconciliation of essential process parameters for an enhanced predictability of arctic stratospheric ozone loss and its climate interactions, Atmos. Chem. Phys. Discuss., to be submitted, 2012.

Weigel, R., Hermann, M., Curtius, J., Voigt, C., Walter, S., Böttger, T., Lepukhov, B., Belyaev, G., and Borrmann, S.: Experimental characterization of the COndensation PArticle counting System for high altitude aircraft-borne application, Atmos. Meas. Tech., 2, 243-258, doi:10.5194/amt-2-243-2009, 2009.

Wilmouth, D. M., Hanisco, T. F., Stimpfle, R. M., and Anderson, J. G.: Chlorine-Catalyzed Ozone Destruction: Cl Atom Production from ClOOCl Photolysis, J. Phys. Chem. A, 113, 1409914108, doi:10.1021/jp9053204, 2009.

Yang, P., Liou, K. N., Wyser, K., and Mitchell, D.: Parameterization of the scattering and absorption properties of individual ice crystals, J. Geophys. Res., 105, 4699-4718, doi:10.1029/1999JD900755, 2000. 